\title{
Reproductive Health Situation in South Africa: Emerging Policy Issue
}

Journal of Asian and African Studies 2018, Vol. 53(7) 1032-1042 (C) The Author(s) 2018 Reprints and permissions: sagepub.co.uk/journalsPermissions.nav DOI: 10.1 I 77/0021909618762544 journals.sagepub.com/home/jas

@SAGE

\author{
A Sathiya Susuman \\ Department of Statistics and Population Studies, University of the Western Cape, South Africa
}

\begin{abstract}
South Africa is still lagging behind with health outcomes, especially when it comes to accessing treatment, prevention and care for reproductive health issues despite the significant progress made with regard to certain aspects of the health system. This study explores the reproductive health situation in South Africa. The study explores some selected health outcomes and related policies from the nine provinces in South Africa. The results indicate that, despite the progress made in the fight against HIVIAIDs and other healthrelated problems, little has been done to improve maternal health care.
\end{abstract}

\section{Keywords}

Health care service, health care utilization, quality, delivery, National Population Policy, South Africa

\section{Introduction}

The provision of high-quality and affordable health care services is an increasingly difficult challenge. Due to the complexities of health care services and systems, investigating and interpreting the use, costs, quality, accessibility, delivery, organization, financing, and outcomes of health care services is key to informing government officials, insurers, providers, consumers, and other decision-makers about health-related issues. Every initiative taken to improve quality and outcomes in health systems has, as its starting point, some understanding of what is meant by 'quality'. Without this understanding, it would be impossible to design the interventions and measures used to improve the population. Processes that affect the population policies in South Africa can be traced from the socio-demographic differentials among racial groups. The National Population Policy of 1998 highlights the shift to maintainable human development, which places the population at the centre of development and concerns people as the driving force and ultimate beneficiaries of development. The National Population Policy of South Africa was officially adopted by Parliament in April 1998 (Ellis and Adams, 2009). The Population Policy primarily seeks to influence the country's population trends in such a way that they would be dependable with the achievement of

\section{Corresponding author:}

A Sathiya Susuman, Department of Statistics \& Population Studies, University of the Western Cape, 7530 Bellville, Cape Town, South Africa.

Email: sappunni@uwc.ac.za 
sustainable human development. In addition, to meet the objectives of the policy, it was imagined that government departments at national and provincial levels would design interventions that would lead to the achievement of these objectives.

This research will focus on development planning and policy based on quality of care in South Africa. Even though South Africa has made significant progress with regard to certain aspects of the health system, such as the establishment of a unified national health system and the development of progressive public health legislation and policies, the country is still lagging behind with health outcomes and in particular the achievement of Millennium Development Goals 4, 5 and 6. Primary Health Care (PHC) is a philosophy that governs the principles and strategies for the organization of health systems, around the central focus of health being a fundamental human right. This was proposed by the World Health Organization (WHO) in the Alma Ata Declaration of 1978. The health sector continues to face significant challenges, which include a quadruple burden of disease, inequitable distribution of health resources, emphasis on curative healthcare, dependence on the public healthcare system by the majority of the population and weaknesses in the areas of health resources and leadership.

This paper presents the quality of care related to (a) Population Policy, (b) reproductive and child health programmes as well as (c) development planning and policy. Information from these three components will assist future research regarding these matters within South Africa.

\section{Population policy}

Population policy is defined as purposeful measures aimed at affecting demographic processes, notably fertility, mortality and migration (Demeny, 1975). The National Population Policy mainly strives to influence the country's population trends in such a way that they would be consistent with the achievement of supportable human development, and to meet the objectives of the policy. The vision of this policy was to emphasize the attainment of a high and equitable quality of life for all South Africans, the balance between population trends, sustainable socio-economic development and the environment. Reason being the persistent lack of clarity in the discussions of Population Policy as to the basic principles on which public intervention in demographic matters may be justified. The objectives of Population Policy is the systematic integration of population factors into all policies, plans, programmes and strategies aimed at enhancing the quality of life of the people at all levels and within all sectors and institutions of government. Also, the co-ordinated, multi-sectorial interdisciplinary and integrated approach in designing and implementing programmes and interventions that affect major national population concerns. These two objectives need reliable and up-to-date information on population and human development to inform policymaking and programme design, implementation, monitoring and evaluation. In addition, this policy requires no demonstration that in many societies, a large proportion of human actions concerning fertility, mortality, and migration take place outside of government control. Population policy has been designed and conceived as integral to development of policies and strategies. It also articulates the Government's position on the relationship between population and the development thereof. Whereas sustainable human development is the central theme, and organizing principle of policy which states that the development challenge is viewed in terms of meeting the needs of the present generation and improving their quality of life without destroying the environment, in order to avoid compromising the ability of future generations to meet their own needs. The implementation of the policy was aimed at developing the necessary demographic and interpretative capacity in all relevant departments. The policy was to ensure the undertaking of adequate demographic analysis and related policy interpretations to support the policy-making and planning needs of each sectorial department. The limited availability of data disaggregated by sex, as well as of basic 
statistics on internal and international migration is striking. According to Ellis and Adams (2009), 'one of the Population Policy's strategies is to enhance reproductive health and rights that would lead to improved quality of general health especially for women, children, adolescents and other vulnerable groups'. Where, sexual and reproductive health can be expressed in terms of categories such as infertile couples; couples with an unmet need for contraception; teenage pregnancies; newborn deaths; life-threatening maternal morbidities; and maternal deaths including those from unsafe abortion.

Another concern of the policy is poverty. The proposed strategy to improve it was stated as reducing poverty and socio-economic inequalities through meeting people's basic needs for social security, employment, education, training and housing, as well as the provision of infrastructure and social facilities and services. Secondly, a strong rural policy should be introduced to ensure that those who remain in rural areas are not locked into poverty and that their life chances are improved (Dlamini, 2015). The National Development Plan advocates for the creation of more jobs through agricultural development, based on effective land reform and the growth of irrigated agriculture and land production, and developing industries such as agro-processing, tourism, fisheries and small enterprises where potential exists. Moreover, a strong urban development policy that caters for the increasing numbers of people by ensuring that the necessary infrastructure and services are in place for a growing urban population (Dlamini, 2015 Improving the quality, accessibility, availability and affordability of PHC services, including reproductive health and health promotion services (such as family planning), to the entire population in order to reduce mortality and unwanted pregnancies, with a special focus on disadvantaged groups, currently underserved areas, and adolescents; and eliminating disparities in the provision of such services). '(Dlamini, 2015)'.

\section{Reproductive and Child Health Programmes in rural areas of South Africa}

Rural population (\% of total population) in South Africa was reported at $34.7 \%$ in 2016, according to the World Bank collection of development indicators, compiled from officially recognized sources. The rural communities are the most disadvantaged in terms of accessing good quality health care. The South African constitution section 27, indicates that every individual has a right to access proper healthcare services. The rural communities are facing challenges of diseases like HIV/AIDS and infant mortality due to the meagre availability of few public and private clinics compared with those in urban areas. Rural communities are not well provided for with these facilities, and where it does exist especially the private-health-care, most of the health specialists run cash practices.

Even though there had been many clinics built after 1994 in the rural areas, the problem remains with the distribution of facilities per population in those given communities (Gaede and Versteeg, 2011). A recent policy development of South Africa has included the restructuring of the PHC system. The policy has been positively received by the health professionals in these rural areas; however, they are not $100 \%$ sure if it will work because of the previous policies that the Government had failed to implement. It is said that South Africa has not paid much attention to rural health compared with other countries globally. India has formulated what is called a 'rural health mission' with the aim of improving the health care system of people living in the rural areas. The United Kingdom and Australia also have their programmes that are implemented in order to improve access to healthcare facilities. In a report released by the World Bank on geographical imbalances in the distribution of health workers, it is stated that 'the rural health facilities are in short of numbers and skills are needed in most sub-Saharan countries'. According to the recommendations made by WHO about the health worker density of 2.28 health workers per 1000 , to achieve the Millennium Development Goals, South Africa is below the minimum 
nationally and it is even worse in the rural areas - with the North West Province (mostly rural) having 0.24 doctors and 0.81 nurses per 1000 people (Versteeg et al., 2013). Even though the South African Government is spending a lot on building an improved health system compared with some middle-income developing countries, there is no improvement in maternal health and the increasing numbers of mortality rates. In September 2000, world leaders signed an agreement on eight Millennium Development Goals in order to better the lives of women, men and children in their countries. The agreement was to reduce child mortality by $67 \%$ and to improve maternal death by reducing it by 75\% between 1990 and 2015 (Black et al., 2016). For many years, reproductive, maternal, new-born and child health has been a very important topic to most governments in low-income and middle-income countries. An analysis that was conducted by reproductive, maternal, new-born and child health $(\mathrm{RMNCH})$; the assistance to those countries facing difficulties has increased from US\$3.5 billion in 2006 to $\$ 8.7$ billion in 2012 that alone is showing a significant progress by global communities.

Asian and sub-Saharan African countries have high maternal deaths, caused by illness like HIVrelated maternal death, which is very high in sub-Saharan Africa (6.4\%). Despite the progress that is being made by all countries, South Africa is still struggling to reduce its maternal and child mortality, especially in rural areas. According to a report released by Global Health in 2007, infant mortality rates in rural areas were 71.2 per 1000 live births compared with 43.2 in the urban areas. Similarly, a report on women's health in the Mpumalanga province indicates that more women were dying during childbirth with an increasing number of stillbirths (Cullinan, 2013). Diseases like HIV/AIDS and tuberculosis (TB) are common among pregnant women, which is a major contributing factor towards child mortality and maternal death. The Government in its National Strategic Plan 2011 promised to deliver anti-retroviral (ARV) treatment to all South Africans in need including the rural communities. More than $80 \%$ of women living with HIV are in their reproductive years and will continue to want to have babies after knowing their HIV status (Delvaux and Nöstlinger, 2007). The increasing availability of antiretroviral treatment and improvement in health status may lead to a renewed interest in sexual relations and the desire to have children for women and men living with HIV and AIDS. The implementation of programmes that are monitoring TB and HIV care has shown some success in rural areas. These programmes come along with lot of literature, with lots of policies in connection with health care services and health care utilization. Some of these policies need to be reworked or followed up with suitable consideration. This study will, therefore, explore some selected health outcomes and related policies. It will also explore which of the policies did not function well or which one is functioning properly, and how it could be promoted or improved with possible solutions regarding policy concerns in South Africa.

\section{Materials and methods}

This study depends solely on secondary information and relevant key indicators. There are nine provinces in South Africa such as Gauteng, Western Cape, KwaZulu-Natal, Limpopo, Northern Cape, Free State, Eastern Cape, North West, and Mpumalanga with a total population 2011 of 55.65 million in 2016 according to the Community Survey. An overview of modest rates with a comparison of figures of key selected health outcomes by provinces were provided in South Africa. An electronic search was conducted on all health-related published articles, letters, abstracts and reviews, using the electronic databases MEDLINE, PubMed and Google Scholar in August 2016. Searches were limited to articles published in English. The databases were searched using a health-related term (health care services, health care utilization, health care quality, health delivery, National Population Policy, maternal mortality, child health, infant mortality). 
Table I. Comparison of selected key health outcomes in South Africa.

\begin{tabular}{|c|c|c|}
\hline Characteristics & (Less average) & (High average) \\
\hline $\begin{array}{l}\text { Maternal Mortality Ratio per } \\
100,000 \text { live births }\end{array}$ & Gauteng 112 & Free State 313 \\
\hline $\begin{array}{l}\text { Infant mortality rate per } \\
1000 \text { live births }\end{array}$ & Western Cape 22.9 & Eastern Cape 57.I \\
\hline Tuberculosis cure rate & Gauteng 78.7 & North West 58.3 \\
\hline HIV prevalence (age I5-49) & Western Cape 9.7 & KwaZulu-Natal 25.7 \\
\hline Low birth weight & KwaZulu-Natal 5\% & North West $38.3 \%$ \\
\hline Tuberculosis ${ }^{2}$ & Limpopo 249 per 100,000 & $\begin{array}{l}\text { Western Cape } 911 \text { per } \\
100,000\end{array}$ \\
\hline Teenage pregnancy $(13-19)^{3}$ & Gauteng 34.15 per 1000 & Eastern Cape 68.8I per 1000 \\
\hline Under 5 mortality 4 & Limpopo II 0 per 1000 & Western Cape 78 per 1000 \\
\hline AIDS $^{5}$ & Northern Cape 7.8\% & KwaZulu-Natal $17.4 \%$ \\
\hline Cancer incidence ${ }^{6}$ & Northern Cape 2.2\% & Gauteng $23.7 \%$ \\
\hline
\end{tabular}

\section{Results}

In a review of the state of health in South Africa, the findings were that there is good progress in fighting HIV, AIDS, TB and malaria. Conversely, there is no progress in improving maternal health and mortality of children less than 5 years of age is worsening. There are huge differentials between provinces that are mostly rural and urban ones. Table 1 above illustrates those differences.

The results further indicate that under 5 mortality rates were high, followed by teenage pregnancy and infant mortality rate as presented in Figures 1 and 2.

\section{Global support}

The United Nations (UN) has noted that, globally, children in rural areas are at the greater risk of dying even in those countries that have low mortality rates. To deal with rural health challenges, government has developed many programmes with the aim of developing rural health systems. The main priority is to reduce maternal death and child mortality rates. In 2011 the National Department of Health identified the problematic issues including a detailed chapter on developing the rural health. In South Africa, the UN has started a programme that is focusing on HIV-positive youth in the provinces of KwaZulu-Natal, Limpopo and Eastern Cape, in partnership with the national and provincial Department of Health, the Department of Social Development, UN Fund for International Partnerships (UNFIP), UN Children's Fund (UNICEF) and UN Population Fund (UNFPA). These programmes are helping rural youth to take part in non-governmental organizations giving community and home-based care and support to their respective communities.

In 2014 a Partners Forum, led by Graca Machel, launched a programme called 'the every newborn action plan', which was approved by health ministers from across the world at the May 2014 World Health Organization. In the same launch the Minister of Health Dr Motsoaledi said 'we want to reduce child and maternal mortality among poor people but the design of the healthcare and financing is in favour of the rich, and we believe universal coverage is the only method (that will) reverse that'. The aim of the programme was to lower the neonatal death rate to 10 or fewer per 1000 live births and decrease stillbirth rates to 10 or fewer per 1000 births (Makholwa, 2014). 


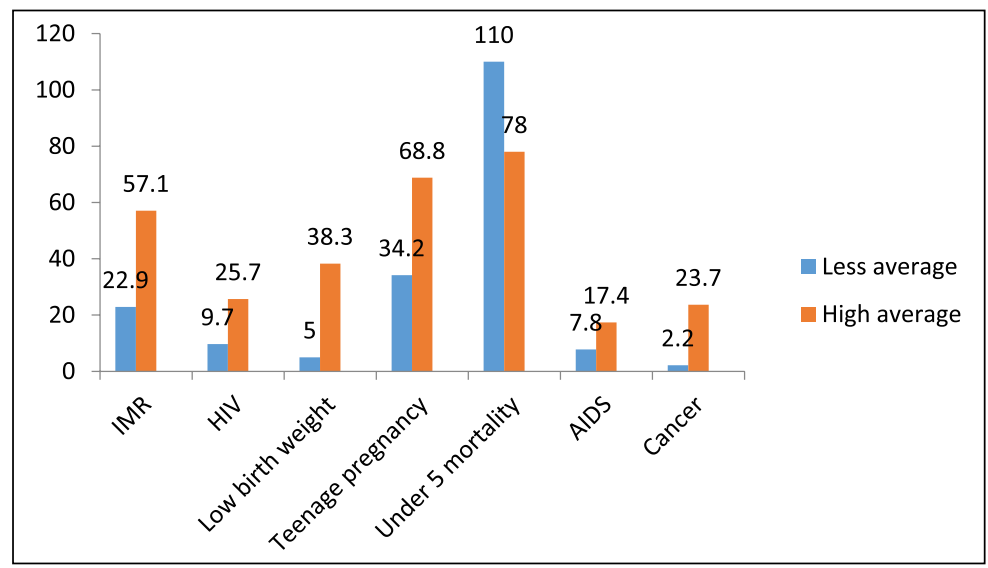

Figure I. Key health indicators in South Africa in 2015. Infant Mortality Rate (IMR):

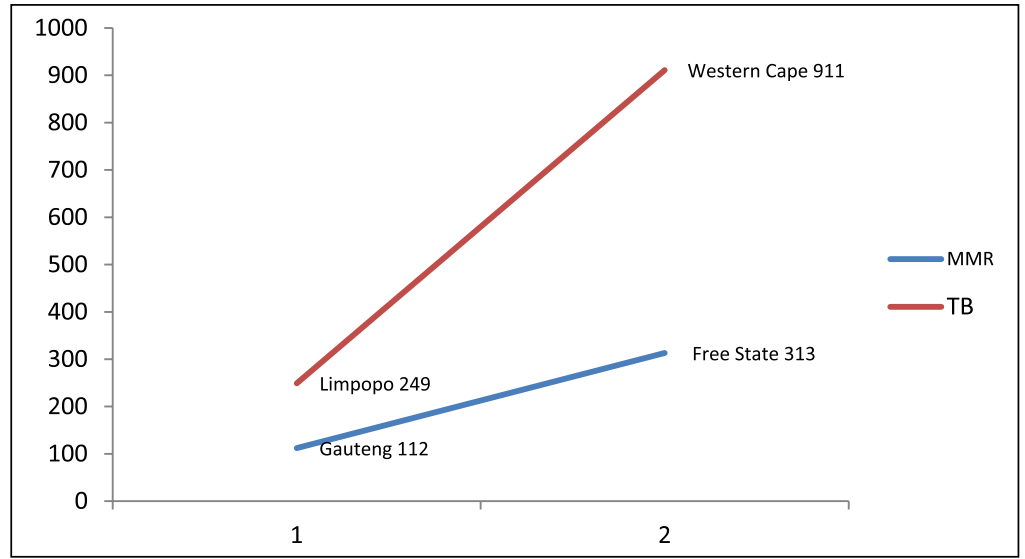

Figure 2. Maternal Mortality Ratio (per 100,000 live births) and tuberculosis (per 100,000 populations) in South Africa 2015.

MMR: Maternal Mortality Ratio; TB: tuberculosis

\section{Reproductive health improvement}

Since the introduction of prevention of mother-to-child transmission (PMTCT) in early 2001, South Africa has made great progress; the availability of different types of ARVs, and the programme is running in the entire country. HIV/AIDS in the country has decreased to $3.5 \%$, though the mortality rate has not changed. By $2010,98 \%$ of PMTCT programmes were offered in health institutions in the country. According to the report that was released by Human Sciences Research Council on HIV prevalence incidence and behaviour Survey in 2014, maternal and child morbidity declined due to the PMTCT services.

In November 2014, President Jacob Zuma launched operation 'Phakisa' which is to help the government quicken the implementation of important programmes such as delivering best infrastructure in public health facilities. The most important of all is to help people living in the rural 
areas to access basic health services like those in urban areas; to provide clinics that offer women information about sexual health education, which targets women and teenagers who are pregnant through health talks; provide a clear understanding of the importance of attending family planning clinics and bringing their children for immunisation; to improve technology of using cell phones among women in rural areas in order for women to educate each other on social networks or be able to receive information through their clinics; to reduce inequalities among people who are living in rural areas and those in urban areas.

The national Department of Health is doing its best to reduce child death, in April 2014 they introduced a programme called 'Mom Connect' that registers pregnant women by using a cell phone: a woman has to send a 'please call me' to the department and they will call to capture her details and keep track of their progress. The programme aims to empower women about information and instructions important to make sure that they have a healthy pregnancy and in order for them to have healthy deliveries. After giving birth, the information then changes as they now learn how to take care of the newly born child. This continues until the child is one year old. Within a period of 8 months, the national department recorded 383,354 pregnant women, and this was regarded as a big number in the world. The aim of the project is to register 1.2 million women who get pregnant every year. The system of reducing long queues at the clinics was introduced where patients are registering their name on collection point and they may collect their medicines, a total number of 383,989 patients were already on the system at the end of April 2015, and the department has set a target of over 1 million people.

The South African Government is in the process of introducing a National Health Insurance; the aim is to unite the public and the private sector to ensure that the distribution of health infrastructure is accessible by all South African citizens. It is agreed that the standard health care must be free at the point of service, but if it must be paid at the procedure that has yet to be established by all parties involved. It is also suggested that it must be paid via VAT increase and be compulsory contributions by working individuals. The challenge that is facing this so called 'Universal Service' is the shortage of professionals, doctors and specialists who are needed globally. Back in 2012, in a pilot study that was conducted in some districts, doctors were complaining about the working conditions, lack of safety and no defined level of salary. And there was no relationship between the companies providing the doctors (providers) and the Department of Health. The pilot was criticised for not giving answers to the difficult questions on how to implement it. The failing of the pilot has raised many issues in terms of which models must be used and the Government spending a lot of money to fix health facilities before conducting another pilot.

\section{Development planning and policy}

The World Bank, World Development Report 1993; Investing in Health (World Bank, 1993) argues that the most important contribution to advancing the broad vision of health is to reduce the burden of disease and disability. The report further focuses on the contribution of research in reducing this burden of disease. According to Health Research Policy (2001: 1) in South Africa the single most important determinant of an effective health research system is the issue of governance and leadership (Department of Health, 2001). The limited human and financial resources within developing countries have led to a mismatch between funding and health needs, and the inappropriate concentration of research expertise. The poor economic performance of the poorest countries and the inappropriate concentration of research expertise have resulted in a decline in the real value of research funding. On a global scale, the inequitable nature of health research is characterized by a wider gap of 90-10 margin. That is, less than 10\% of health research funds were spent on $90 \%$ of the global burden of disease (Department of Health, 2001: 11). 
Through quality care reports, service providers can provide information and improve interaction with their community. The aim is to meet diverse quality and safety health literacy needs by making the reports as accessible and easy to understand as possible. In 2013, the quality and safety reporting landscape altered with the introduction of South Africa's Health Services Safety and Quality Accreditation Scheme, including the National Safety and Quality Health Service Standards (Department of Health Annual Report, 2013-2014). These standards require health service providers to demonstrate performance across an increasingly comprehensive range of quality and safety criteria. When preparing quality care reports, services should keep in mind that quality and safety standards across the sector consistently require that service providers inform their community on the quality and safety of care and treatment provided. An important aspect of continuity of care includes how services ensure that access and discharge or transfer practices meet the needs of consumers. Public health services should report on their progress towards an organizational policy for providing safe, high-quality end-of-life care. The South African Government, which was a signatory to the Alma Ata Declaration, has adopted the PHC philosophy and the WHO definition of health. The South African legislation, starting with the supreme law of the land, the constitution, espouses the values of human dignity, equality, rights and freedoms and social justice in order to ensure accountability, responsiveness and openness in a democratic society, while seeking to improve the quality of life of all citizens. Section 27 in the Bill of Rights states that 'everyone has the right to have access to health care services, including reproductive health care; sufficient food and water; and social security and the state must take reasonable legislative and other measures, within its available resources, to achieve the progressive realization of each of these rights.'

The National Health Act (Act 61 of 2003) is an overarching legislative framework that provides for the establishment of the national health system, and sets out the rights and duties of health care providers, health workers, health establishments and members of the public (National Health Act, 2003). The objective is to protect, respect, promote and fulfil the rights of South Africans, with special reference to vulnerable groups (such as women, children, older persons and persons with disabilities). The progressive realization of the constitutional right of access to health care services is mandated, within the context of available resources. The Minister of Health, within the limits of available resources, has to protect, promote, improve and maintain the health of the population by ensuring the equitable provision of essential health services, which at least include PHC services. The public health sector provides free health services to pregnant and lactating women and children below the age of 6 years, who are not members of medical aid schemes. The duties of the public include adhering to the rules of the health establishment, providing accurate information, and treating health care workers with respect and dignity. The rights of the public include the right to participate in decisions affecting their health, undergoing an informed consent process, and the right to refuse treatment.

\section{Discussion}

Our study findings show that the actual value of reproductive health has not been fully realized and utilized in the African context. The current situation of reproductive health has been a result of the fact that policy-makers, planners, programme organizers are not often involved in the initial phase of most policies, and the fact that results from health research are not adequately disseminated. As a response to the growing variation in reproductive and child health programmes, many countries such as the United States, India and Ethiopia have partnered with UNICEF to launch the 'Child Survival Call to Action'.

Under this programme, they are calling on countries around the globe to refocus their health systems on improving access to high-quality services for those suffering from a disproportionate 
burden of disease, especially the rural, poor and marginalized populations and to equally implement a better way of monitoring the progress of these programmes in the most disadvantaged areas (UNICEF, 2012). For South Africa to prioritize disadvantaged areas, the Government should decentralize health care funding. It has been noted that decentralization empowers local areas to use health care resources as they like, with the assumption that targeting and monitoring will take place within a focused geographic area. Stratifying health care services by urban versus rural residence does not necessarily reach those in need. Regardless of the challenges in the health care sector, there are opportunities for significant system improvements and progress on the major policy priorities. The Department of Health has policies, programmes and service priorities that aim to promote health and development, and to prevent or reduce risk factors for health conditions associated with tobacco, alcohol and road accidents. Introducing population policies can help a nation attain a better future. The Government of South Africa can do this through the provision of means for women to avoid unwanted pregnancies - by establishing and funding voluntary family planning programmes to provide information and contraceptive services that can help individuals achieve a desired family size. In nations where access to such programmes falls sharply below demand, meeting these needs could sharply reduce the birth rate leading to a proper reproductive health care system.

\section{Conclusion}

This paper concludes by identifying population priorities on which the country's population strategy should focus during the current term of Government, to contribute to the achievement of the targets of the Government's Programme of Action, particularly those identified in the National Development Plan. A number of other priorities could play a big role in campaigning for better access to and use of reproductive health services, especially in rural areas. These priorities could include the inclusion of the mass media in terms of broadcasting information relating to maternal health services and the importance of such health care services, educational programmes aimed at enhancing the literacy skills of maternal women (particularly in rural areas), implementing better youth reproductive health policies that are aimed at shaping the livelihoods of women and reduce teenage pregnancy. To sustain satisfactory budget allocation for the prevention and treatment of HIV and AIDS and improving service efficiency and quality of care needs to be strengthened. Furthermost significantly, efforts to improve the quality of care need to be driven from the front, by political and health service leaders, who can inspire health workers to have the biggest possible impact on the health of the communities they serve.

\section{Acknowledgements}

The author would like to thank anonymous reviewers for their incredible comments and suggestions.

\section{Funding}

The author(s) received no financial support for the research, authorship, and/or publication of this article.

\section{Notes}

1. Labadarios D (ed) (2008) The National Food Consumption Survey - Fortification Baseline (NFCS-FB): The knowledge, attitude, behaviour and procurement regarding fortified foods, a measure of hunger and the anthropometric and selected micronutrient status of children aged 1-9 years and women of child bearing age: South Africa, 2005. Pretoria: Directorate: Nutrition, Department of Health.

2. National Tuberculosis Management Guidelines 2009, Department of Health, South Africa 2009. 
Available at: http://familymedicine.ukzn.ac.za/Libraries/Guidelines_Protocols/TB_Guidelines_2009. sflb.ashx. See more at: http://www.tbfacts.org/tb-statistics-south-africa/\#sthash.ZAwqDP7O.dpuf

3. Panday S, Makiwane M, Ranchod C, et al. (2009) Teenage pregnancy in South Africa: with a specific focus on school-going learners. Pretoria: Department of Basic Education.

4. 2007 Community Survey, statistics of South Africa.

5. Shisana O, Labadarios D, Simbayi LC, et al. (2015) South African national HIV prevalence, incidence and behaviour survey, 2012.

6. Available at: http://www.cansa.org.za/files/2016/01/Fact-Sheet-Health-Profile-South-Africa-RelatedInformation-Jan-2016.pdf

\section{References}

Black RE, Laxminarayan R, Temmerman M, et al. (2016) Reproductive, maternal, newborn, and child health: Key messages from Disease Control Priorities 3rd Edition. Lancet 388: 2811-2824.

Department of Health (2001) Health Research Policy in South Africa. Department of Health. Available at http://www.gov.za/sites/www.gov.za/files/healthresearch_0.pdf, Pretoria (accessed September 2016).

Department of Health (2010) Negotiated Service Delivery Agreement (NSDA): A Long and Healthy Life for All South Africans. Pretoria: Department of Health.

Department of Health Annual Report (2013-2014) Annual Report 2013-2014. Available at http://www.gov. za/sites/www.gov.za/files/Department_of_Health_Annual_Report_2014.pdf, Pretoria, (accessed on 14 September 2016).

Delvaux T and Nöstlinger C (2007) Reproductive choice for women and men living with HIV: Contraception, abortion and fertility. Reproductive Health Matters 15(29): 46-66.

Demeny P (1975) Population policy: The role of national governments. Population and Development Review 1(1): p.1-15.

Dlamini MB (2015) Department of Social Development [Online]. Available at: www.dsd.gov.za/index2. php?option $=$ com_docman\&task $=$ doc_view\&gid $=579 \& I t e m i d=39$ (accessed 6 August 2016).

Ellis C and Adams W (2009) Towards a 10-Year Review of the Population Policy Implementation in South Africa (1998-2008): Families, Families and Children. South Africa: Department of Social Development.

Gaede B and Versteeg M (2011) Chapter 9 - The state of the right to health in rural South Africa. In: Padarath A and English R (eds) South African Health Review. Durban: Health Systems Trust, pp.99-106.

Labadarios D (2008) The National Food Consumption Survey Fortification Baseline (NFCS-FB-1), South Africa, 2005. South African Journal of Clinical Nutrition 21(3): Supplementary 2.

Makholwa, Andile (2014) South Africa to miss target to decrease child and maternal deaths, Available at http://ftp.bhfglobal.com/sa-miss-target-decrease-child-and-maternal-deaths.

Naledi T, Barron P and Schneider H (2011) Primary Health care in SA since 1994 and implications of the new vision for PHC re-engineering. In: Padarath A and English R (eds) South African Health Review. Durban: Health Systems Trust.

National Health Act (2003) National Health Act, 2003. Act No. 61, 2003. Available at http://www.safmh.org. za/documents/policies-and-legislations/NATIONAL\%20HEALTH\%20ACT.pdf (accessed 14 September 2016).

Schaay N, Sanders D, Kruger V, et al. (2011) Overview of Health Sector Reforms in South Africa. Department for International Development (DFID), London: Human Development Resource Centre (HDRC), Assest Publishing, DFID Human Development Resource Centre.

Shapiro K and Sunanda R (2007) Sexual health for people living with HIV. Reproductive Health Matters 15: $67-92$.

UNICEF (2012) Chid Survival Call to Action: Ending Preventable Child Deaths. UNICEF. Available at: http://5thbday.usaid.gov/pages/responsesub/roadmap.pdf, accessed on (accessed 14 Sepetember 2016).

Versteeg M, du Toit L and Couper I (2013) Building consensus on key priorities for rural health care in South Africa using the Delphi technique. Global Health Action 6: 19522. 
WorldBank,2013.Poverty Prosperity,Endextremepoverty2030 and promote shared prosperity, Availableat: http://siteresources.worldbank.org/EXTANNREP2013/Resources/9304887-1377201212378/ 9305896-1377544753431/1_AnnualReport2013_EN.pdf

\section{Author biography}

A Sathiya Susuman is Professor (Associate), Faculty of Natural Sciences, Department of Statistics and Population Studies, University of the Western Cape, Bellville 7530, Cape Town, South Africa. He has been engaged in teaching and research in Indian and Africa since 2001. His research interests include technical demography, fertility, mortality, gender, reproductive health, vulnerable diseases, HIV/AIDS, health policy and public health. 